PARTEIL.

Diagramas das classes de signos 



\section{II.1. Modelos desenvolvidos por Peirce}

Nesta seção, são analisados dois diagramas elaborados por Peirce para as dez classes de signos (MS 540: 17, CP 2.264, EP 2: 296; L 463:146, CP 8.376, EP 2: 491). Conforme mencionado na Seção I.1.3, um deles se refere à divisão descrita no "Syllabus", em 1903; o outro diagrama aparece nos esboços de uma carta para Lady Welby, escrita no final de dezembro de 1908. Apresentamos aqui não apenas os modelos, tal como foram publicados nos Collected papers e no The essential Peirce, mas também uma série de esboços para estes diagramas, encontrados em seus manuscritos. Eles servem de base para a discussão a respeito dos diagramas dinâmicos 10cubes e 3N3 nas seções finais deste livro.

\section{II.1.1. O modelo do "Syllabus" de 1903}

Como discutimos no capítulo I.1, Peirce apresenta, no "Syllabus", a divisão dos signos em dez classes, baseada em três tricotomias. Depois de descrever as classes, ele faz um diagrama em que as classes aparecem em dez quadrados, arranjados de forma triangular (Figura 15), e faz o seguinte comentário:

As afinidades das dez classes são exibidas pelo arranjo de suas designações na tabela triangular aqui apresentada, que possui divisões mais espessas entre quadrados adjacentes que são apropriados para classes similares em apenas um aspecto. Todos os outros quadrados adjacentes pertencem a classes similares em dois aspectos. Quadrados não adjacentes pertencem a classes similares em um aspecto apenas, exceto que cada um dos três quadrados nos vértices do triângulo pertence a uma classe que difere em todos os três aspectos das classes para as quais os quadrados ao longo do lado oposto do triângulo são apropriados. As designações escritas com letras mais finas são supérfluas (CP 2.264). 
Figura 15. Diagrama encontrado em manuscrito de Peirce (MS 540: 17) para seu "Syllabus" de 1903.
Figura 16. O diagrama do "Syllabus" conforme reproduzido nos Collected papers (CP 2.264). A reprodução encontrada no segundo volume do The essential Peirce (EP 2: 296) omite os algarismos romanos.

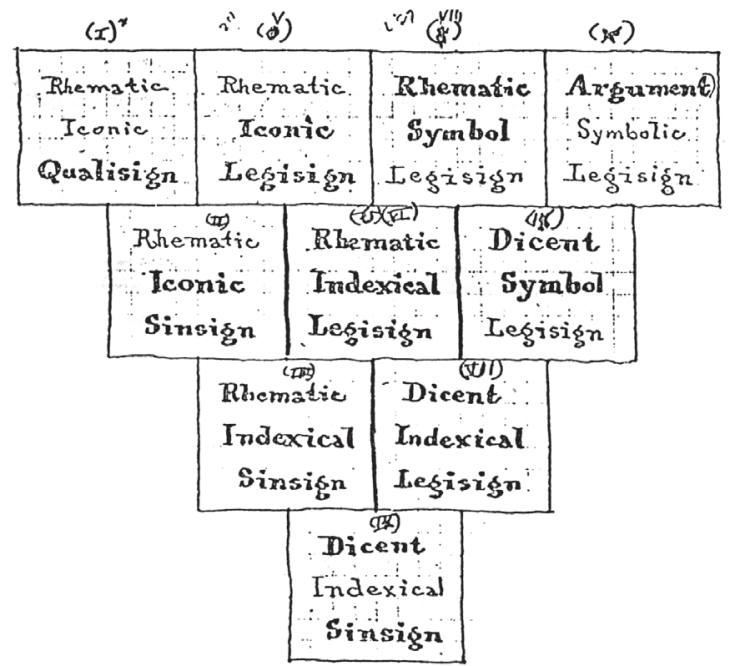

Este diagrama, ao qual nos referimos aqui como "diagrama do 'Syllabus'", foi reproduzido (Figura 16) nos Collected papers (CP 2.264) e no segundo volume do The essential Peirce (EP 2: 296). A numeração em algarismos arábicos foi adicionada pelos editores dos Collected papers para facilitar a referência às dez classes e foi omitida pelos editores do The essential Peirce. Em outras páginas do manuscrito MS 540 (MS 540: 27, 28 e 29, Figuras 17, 18 e 19) e também em uma das páginas do manuscrito MS 799 (MS 799: 2, Figura 20), encontramos os esboços deste diagrama.

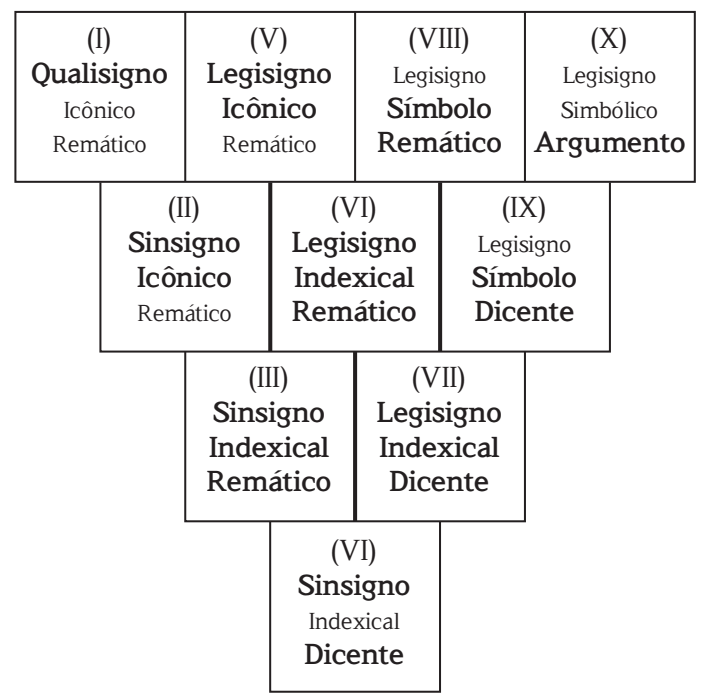



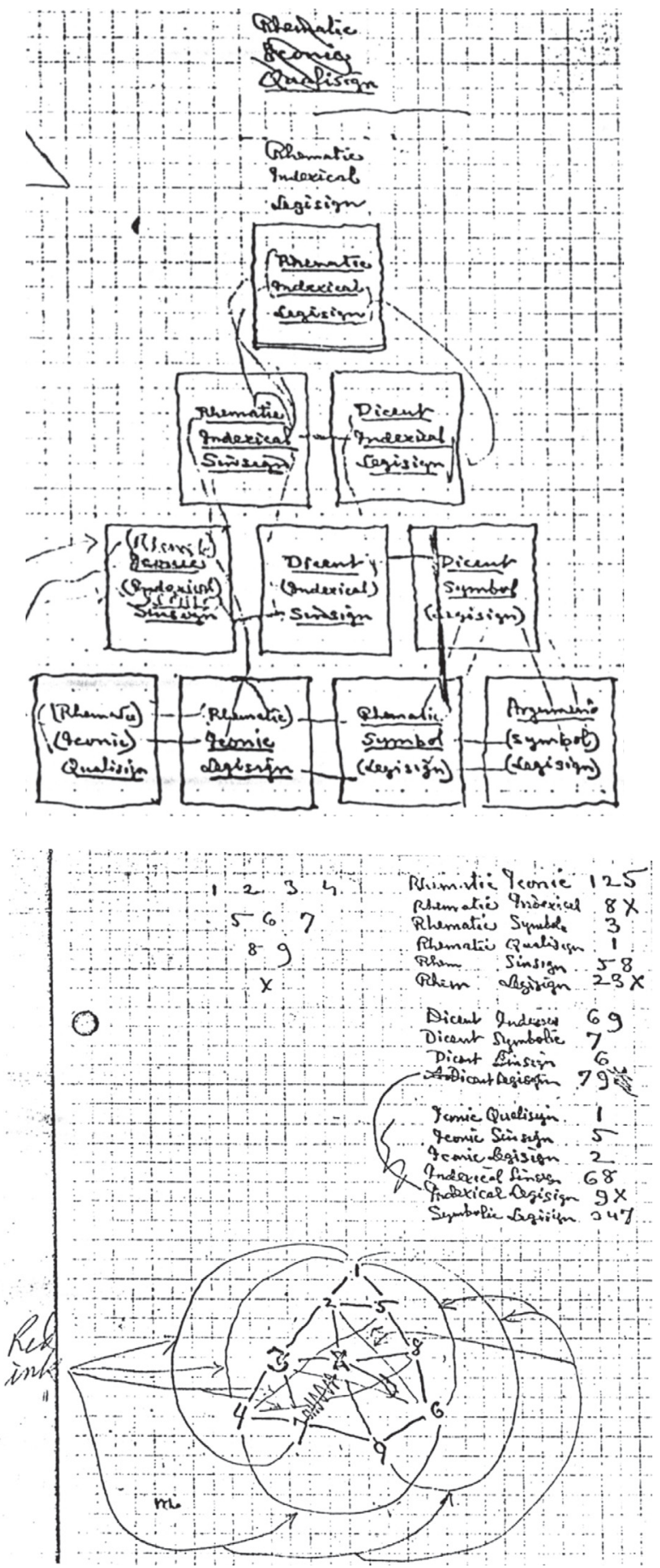

Figura 17. Esboço para o diagrama do "Syllabus" encontrado no manuscrito MS 540: 27.

Figura 18. Esboço para o diagrama do "Syllabus" encontrado no manuscrito MS 540: 28. 
Figura 19. Esboço para o diagrama do "Syllabus" encontrado no manuscrito MS 540: 29.

Figura 20. Esboço para o diagrama do "Syllabus" encontrado no manuscrito MS 799: 2
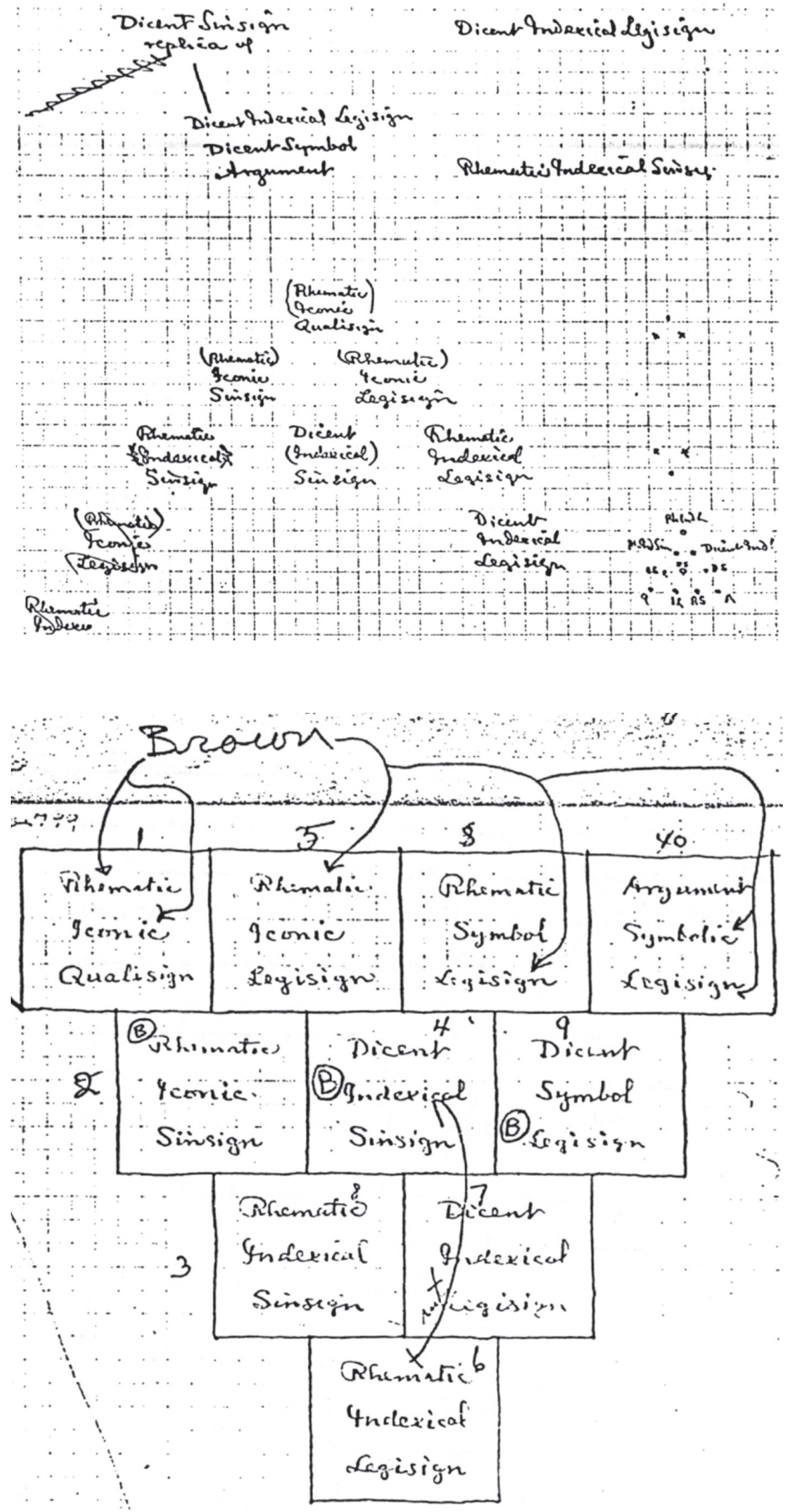
Nos esboços encontrados no manuscrito MS 540 (Figuras 17, 18 e 19), notamos o trabalho de Peirce para obter um arranjo das classes capaz de refletir as relações de similaridade em suas estruturas internas e expressas através das modalidades tricotômicas (por exemplo, classes que são icônicas ou classes que são sinsignos). Os esboços formam uma série de tentativas para chegar ao arranjo final do diagrama do "Syllabus", em que Peirce parece estar finalmente satisfeito com a posição relativa das classes, conforme afirma no trecho citado anteriormente (CP 2.264).

O diagrama encontrado em MS 540: 29 (Figura 19) é o primeiro desta série. Existem quatro tentativas nesta página, mas em nenhuma delas aparecem todas as dez classes. $\mathrm{O}$ arranjo mais completo é aquele que aparece no canto inferior esquerdo da Figura 19, em que a classe dos qualisignos (111) foi colocada no vértice superior de um triângulo apoiado em um dos lados. A Figura 21 mostra a mesma estrutura, com as classes expressas em algarismos arábicos (conforme convenção explicada no final da Seção I.1.1) e romanos (seguindo a mesma convenção adotada pelos editores dos Collected papers para o diagrama do "Syllabus").

No manuscrito MS 540: 28 (Figura 18) encontramos, no alto, à direita, uma lista de pares de aspectos das classes (por exemplo, "remático icônico", "remático legisigno") seguidos por algarismos arábicos e romanos (apenas para o numeral "dez", grafado como "X") que indicam quais classes possuem estes aspectos. A convenção adotada para esta notação é idêntica àquela adotada pelos editores dos Collected Papers (a numeração segue a ordem de apresentação das classes no "Syllabus"). A única diferença é a adoção de algarismos arábicos no lugar de romanos.

À esquerda e abaixo desta lista encontramos dois arranjos triangulares para as classes. $\mathrm{O}$ arranjo à esquerda parece estar baseado na ordem numérica das classes. O arranjo maior, abaixo, parece ser mais uma tentativa de organizar as classes de acordo com sua composição interna. Deve-se notar que a posição das classes I, II, III e V é idêntica àquela que aparece na estrutura do esboço da página posterior (MS 540: 29, Figuras 19 e 21). A posição relativa das classes também é similar àquela encontrada no diagrama do "Syllabus" (para compará-los, basta "girar" este último à esquerda, deixando a classe 111 no vértice superior), com exceção da posição das classes VI (321) e X (333), que se encontra invertida.

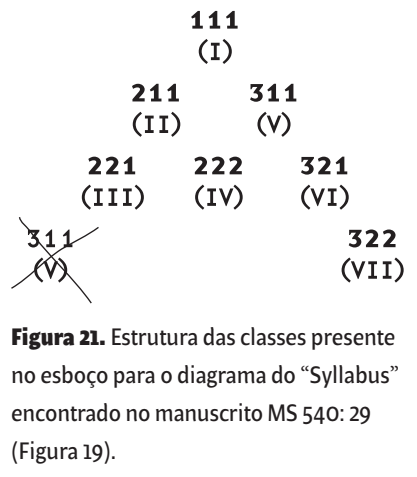

111

211

(II)

311

321

322

(VII)

Figura 21. Estrutura das classes presente no esboço para o diagrama do "Syllabus" (Figura 19). 
Os esboços encontrados em MS 540: 27 (Figura 17) e MS 799: 2 (Figura 20) são os últimos da série que conduz ao diagrama do "Syllabus". Nos dois, a posição das classes é delimitada por quadrados. Em ambos, a posição das classes IV (222) e VI (321) encontra-se invertida, revelando a dificuldade de posicionar a classe VI. Esta é, de fato, a única diferença em relação à posição das classes entre o diagrama do "Syllabus" e o esboço do manuscrito MS 799: 2 (Figura 20). O diagrama do manuscrito MS 540: 27 (Figuras 17), por outro lado, deve ser girado em 180 graus e espelhado, para que a posição das classes coincida com a posição encontrada no diagrama do "Syllabus".

Alguns últimos ajustes na versão final do diagrama do "Syllabus" estão relacionados à diferença aplicada à espessura das linhas divisórias entre as classes e no peso das letras utilizadas para escrever seus nomes. Nesta versão final (MS 540: 17, Figura 15), as divisões das classes II e VI, VI e IX, e III e VII, são mais espessas para indicar que, diferente das outras classes "fronteiriças", estas possuem apenas um aspecto em comum (II e VI, por exemplo, são remas). A variação na espessura das letras utilizadas na descrição das classes segue a tendência para a simplificação de seus nomes explicada na Seção I.1.3.

\section{II.1.2. 0 modelo da carta para Lady Welby}

No esboço de uma carta para Lady Welby, de 24-28 de dezembro de 1908 (L 463: 132-146, CP 8.342-76, EP 2: 483491), Peirce desenhou um segundo diagrama para dez classes de signos. O diagrama reproduzido na Figura 22 (L 463: 146) aparece no post scriptum deste esboço, cujo tema principal são as dez tricotomias. Logo abaixo da figura, Peirce faz o seguinte comentário:

O número acima à esquerda descreve o Objeto do Signo. Aquele acima à direita descreve seu interpretante. Aquele abaixo descreve o Signo em si mesmo.

1 significa a Modalidade Possível, aquela de uma Ideia.

2 significa a Modalidade Atual, aquela de uma Ocorrência.

Para uma análise detalhada deste comentário, ver Farias e Queiroz (2014).
3 significa a Modalidade Necessária, aquela de um Hábito

(L 463: 146, EP 2: 491). ${ }^{29}$ 
Signs divided into Ten classes.

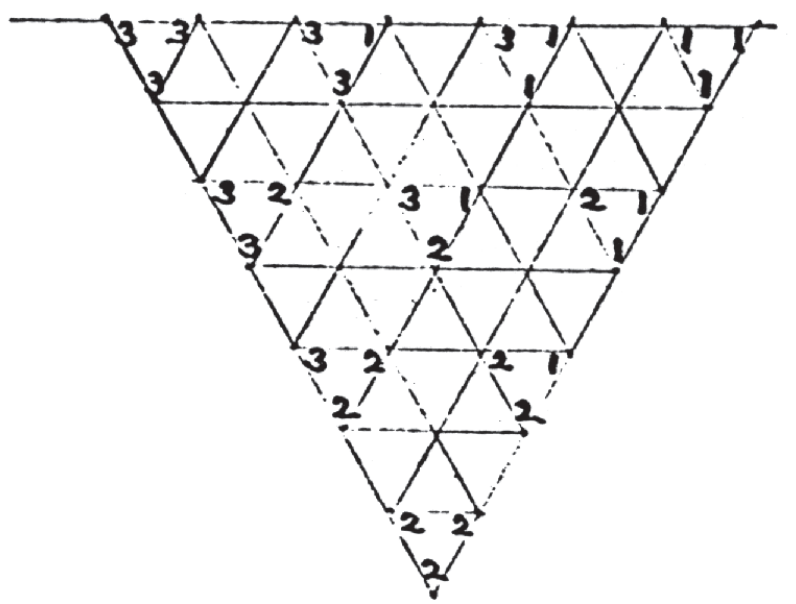

Este diagrama, ao qual nos referimos aqui como "diagrama de Welby", foi reproduzido de forma similar à Figura 23 nos Collected papers (CP 8.376) e no segundo volume da série The essential Peirce (EP 2: 491).

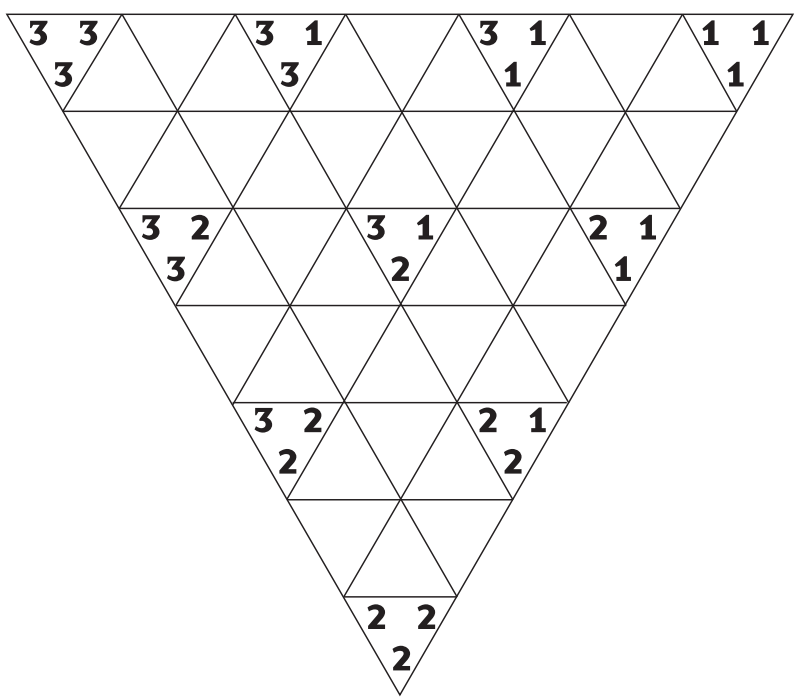

Existem outras versões do diagrama de Welby entre os manuscritos de Peirce. Algumas delas, encontradas em um manuscrito datado de 27 de dezembro de 1908 (MS 399D: 627, Figura 24), parecem ser anotações preparatórias para este diagrama, que
Figura 22. Diagrama para dez classes desenhado por Peirce em um esboço de carta para Lady Welby datado de 24-28 de dezembro de 1908 (L 463: 146).

Figura 23. $O$ diagrama de Welby ( $L 463$ : 146, Figura 22), conforme foi reproduzido nos Collected papers e no segundo volume da série The essential Peirce (CP 8.376, EP 2: 491). 
Figura 24. Anotações preparatórias para o diagrama de Welby encontradas em manuscrito datado de 27 de dezembro de 1908 (MS 399D: 627).
Este parece ser mais um dos muitos esboços para a carta efetivamente enviada que é, ao que tudo indica, aquela datada de 23 de dezembro de 1908, publicada em SS 80-85 e EP2: 478-481 e não contém nenhum diagrama. foi provavelmente desenhado, posteriormente, com a ajuda de uma régua ou instrumento similar (Figura 22). O que parece mais crucial aqui é a posição dos algarismos que identificam cada classe. No conjunto mais abaixo, a posição das classes e dos algarismos que formam as classes é idêntica à que encontramos no diagrama de Welby.

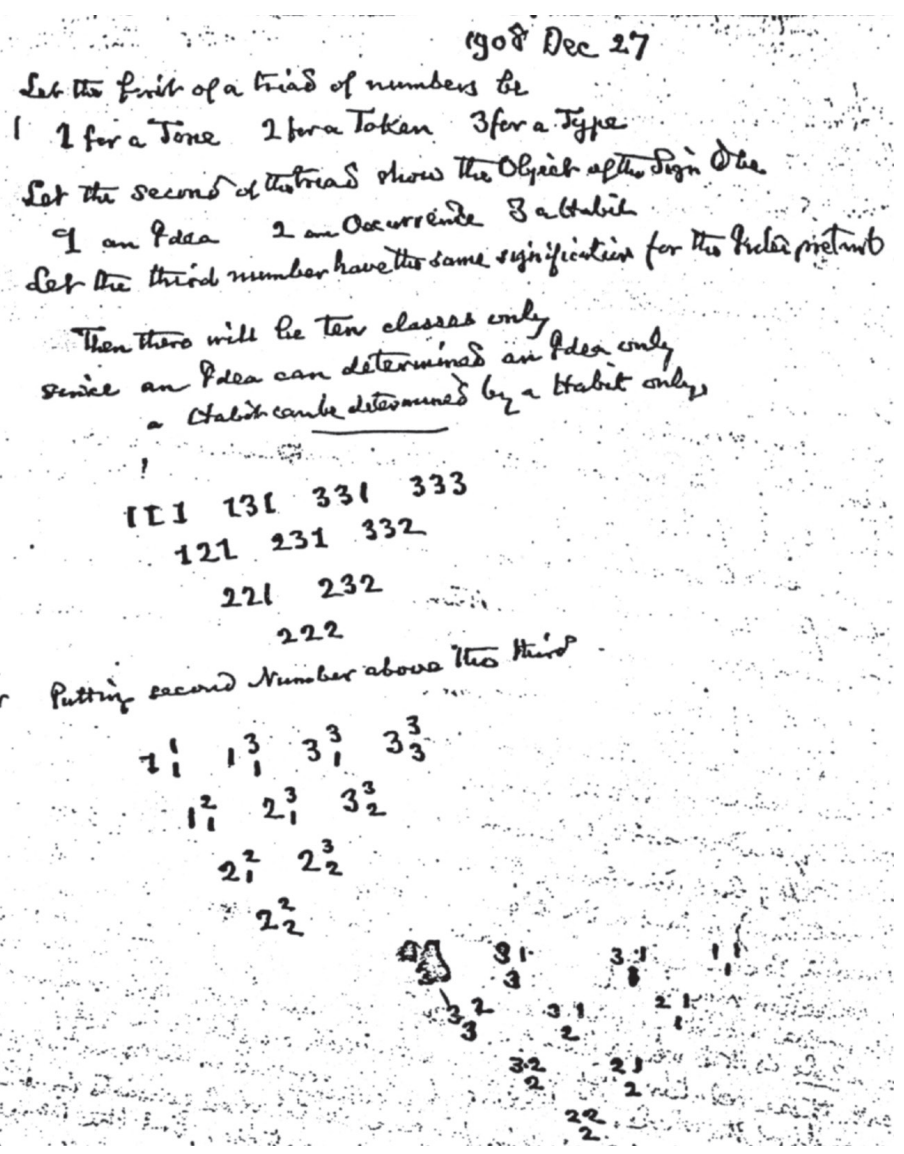

Um desenho muito similar ao diagrama de Welby encontra-se no manuscrito L 463: 155 (Figura 25). ${ }^{30}$ Este parece ter sido desenhado, aproveitando a transparência da folha de papel, a partir da figura encontrada no manuscrito L 463: 146 (Figura 22). Ele é formado por dez triângulos, que contêm as dez classes, e não possui células "em branco", como o diagrama de Welby. Peirce introduz assim este diagrama:

As três divisões de acordo com a Modalidade de Ser do Signo em si mesmo, de seu Objeto, e de seu 
Interpretante não podem gerar 27 classes de Signos, mas apenas Dez; sendo assim, utilizando um pequeno espaço triangular com o vértice para baixo $\nabla$ para descrever cada classe, e denotando-as por

1. Modalidade Possivel

2. Modalidade Atual

3. Modalidade Necessitante,

eu escrevo um destes números em cada um dos cantos do espaço triangular.

O canto inferior para caracterizar o Modo de Ser do Signo em si mesmo.

O canto superior esquerdo para caracterizar o Modo de Ser de seu Objeto.

O canto superior direito para caracterizar o Modo de Ser de seu Interpretante.

Então as Dez classes resultantes serão aquelas apresentadas no Esquema abaixo (L463: 155).
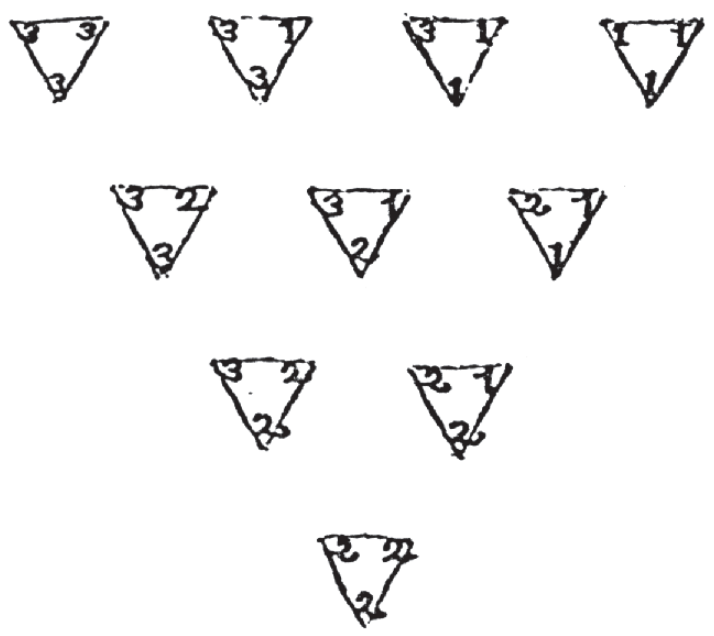

Ao lado do diagrama, Peirce inclui o seguinte comentário: "Um Abstrativo pode apenas ser Descritivo, não Designativo nem Copulativo, enquanto um Copulativo pode apenas ser Coletivo, não Abstrativo nem Concretivo" (L463: 155).

Como observamos (Seção I.1.5), os termos utilizados por Peirce neste comentário referem-se às modalidades das tricotomias Od ([natureza do] Objeto dinâmico) e Oi ([natureza do] Objeto imediato). Este comentário é curioso, uma vez que, como vimos na Seção I.1.6, estas tricotomias só passam a fazer
Figura 25. Diagrama para dez classes encontrado em L 463: 155. Ele parece ter sido desenhado a partir do diagrama de Welby (L 463: 146, Figura 15). 

Houser (1999, comunicação pessoal). parte das classificações, levadas em consideração pelos especialistas, a partir da divisão em 28 classes. Além disso, embora estes diagramas sejam estruturalmente similares ao diagrama do "Syllabus" e suas variações, existem diferenças importantes em relação às classes expressas em suas células.

Se considerarmos que a sequência de leitura dos algarismos que compõem as classes no diagrama de Welby é (i) canto superior esquerdo, (ii) canto inferior, (iii) canto superior direito, isso corresponderia, em termos de ordem de determinação (ver Seções I.1.5 e I.1.6), a afirmar que $O$ determina $S$, que determina I. Isso parece estar em contradição com o que ocorre no diagrama do "Syllabus", onde, conforme discutido na Seção I.1.6, S determina S-Od, que determina S-If. Contudo, se considerarmos que, no diagrama de Welby, o que estamos chamando de $O$ é descrito como "o Modo de Ser de seu Objeto" (e não "a relação com seu Objeto") e, de forma similar, o que estamos chamando de I é descrito como "o Modo de Ser de seu Interpretante", então o que observamos aqui deveria ser entendido como $\mathrm{O}(\mathrm{Oi}$ ou $\mathrm{Od})$ determina $\mathrm{S}$, que determina I (Ii, Id ou If $)$. Esta não é a ordem de determinação que gera as dez classes de signos descritas no "Syllabus", mas também não está em contradição com ela. Como vimos na Seção I.1.6, esta é a estrutura básica da ordem de determinação que dá origem às 28 classes.

Tudo isso nos leva a crer que, embora a estrutura do diagrama de Welby e do diagrama do "Syllabus" sejam muito similares, e embora os dois sejam diagramas para dez classes, as classes apresentadas nas duas figuras podem não ser as mesmas. ${ }^{31}$ A construção do diagrama dinâmico 3N3, apresentado na Seção II.3.3.2, pode ajudar-nos a abordar este tipo de problema. 